\title{
Effect of beach chair position on bispectral index values during arthroscopic shoulder surgery
}

\author{
Sang Wook Lee ${ }^{1}$, Soo Eun Choi ${ }^{2}$, Jin Hee Han ${ }^{1}$, Sung-Wook Park ${ }^{1}$, Wha Ja Kang ${ }^{1}$, and \\ Young Kyoo Choi ${ }^{1}$
}

Department of Anesthesiology and Pain Medicine, ${ }^{1}$ Kyung Hee University Medical Center, ${ }^{2}$ Korea University Anam Hospital, Seoul, Korea

Background: Bispectral index (BIS) monitoring reduces the cases of intraoperative awareness. Several factors can alter BIS readings without affecting the depth of anesthesia. We conducted a study to assess the impact of beach chair position (sitting position) on BIS readings.

Methods: General anesthesia was administered to 30 patients undergoing arthroscopic shoulder surgery. Patients were kept in neutral position (supine) for 10 minutes and BIS readings, mean arterial blood pressure, heart rate, end-tidal carbon dioxide, and end-tidal sevoflurane were recorded. Patients were then shifted to beach chair position. After 15 minutes, data were recorded.

Results: A significant decrease in BIS values $(\mathrm{P}<0.01)$ associated with a position change from neutral position to beach chair position was evident.

Conclusions: BIS values are significantly decreased in the beach chair position compared with the neutral position and might affect interpretation of the depth of anesthesia. (Korean J Anesthesiol 2014; 67: 235-239)

Key Words: Bispectral index, Sitting position.

Received: April 2, 2014. Revised: June 24, 2014. Accepted: June 26, 2014.

Corresponding author: Sung-Wook Park, M.D., Department of Anesthesiology and Pain Medicine, Kyung Hee University Medical Center, 23, Kyungheedae-ro, Dongdaemun-gu, Seoul 130-872, Korea. Tel: 82-2-958-8589, Fax: 82-2-958-8580, E-mail: demerol@khmc.or.kr (c) This is an open-access article distributed under the terms of the Creative Commons Attribution Non-Commercial License (http:// creativecommons.org/licenses/by-nc/3.0/), which permits unrestricted non-commercial use, distribution, and reproduction in any medium, provided the original work is properly cited. 


\section{Introduction}

Awareness during surgery is a leading cause of patient dissatisfaction with anesthesia and a very serious problem for the patient and anesthetist [1]. Intraoperative monitoring of the depth of anesthetic is important to prevent this problem. Use of the bispectral index (BIS) reduces the cases of intraoperative awareness [2-4]. The BIS is a single number calculated from electroencephalogram (EEG)-derived sub-parameters. Several factors can alter BIS readings without affecting the depth of anesthesia. Electrical equipment, specific clinical conditions, abnormal EEG patterns, and neuromuscular blockers (NMB) can interfere with BIS monitoring [5]. Administration of anesthetics including ketamine and isoflurane can cause a paradoxical BIS increase [5-7]. In addition to electrocautery, interference from several electric devices, such as atrial pacer and endoscopic shaver can directly affect BIS monitoring [5,8,9]. Different clinical conditions inc; uding hypoglycemia, hypovolemia, hypothermia, and cerebral ischemia significantly decrease BIS readings [5,10-13]. Furthermore, high EMG activity and neuromuscular blocking drugs (NMBD) can significantly influence BIS monitoring $[5,14]$.

The present study examined the effect on BIS readings during intra-operative position changes. Especially, the change in BIS readings when the position of patients was changed to beach chair (sitting) position in arthroscopic shoulder surgery was explored. The aim was to assess the impact of the beach chair position on BIS values.

\section{Materials and Methods}

After approval from the local ethics committee of our hospital, written informed consent was obtained from patients undergoing arthroscopic shoulder surgery. Thirty patients undergoing arthroscopic shoulder surgery were enrolled. Patients with American Society of Anesthesiology physical status classification I-II, aged between 18 and 60 years between January 2012 and March 2012 were included. Exclusion criteria were previous head injury, neurological disease, hypertension, and glaucoma.

In the operating room, standard monitoring procedures, such as an electrocardiogram, noninvasive arterial blood pressure, oxygen saturation $\left(\mathrm{SpO}_{2}\right)$, and end-tidal carbon dioxide $\left(\mathrm{ETCO}_{2}\right)$, were applied. BIS sensor electrodes (BIS Sensor-Aspect Medical Systems, Natick, MA, USA) were attached to the forehead before induction of anesthesia, and BIS values were measured continuously throughout the surgery using a model A-2000 BIS monitor equipped with software version 3.21 (Aspect Medical Systems, Norwood, MA, USA). After a modified Allen's test and infiltration with $2 \%$ lidocaine, the radial artery on the non-operative arm was catheterized for invasive monitoring of arterial pres- sure for continuously blood pressure monitoring. An arterial pressure transducer was placed at the level of heart regardless of position change.

After determination of baseline values for the BIS and hemodynamic variables, anesthesia was induced with fentanyl $1.5 \mu \mathrm{g} /$ $\mathrm{kg}$, thiopental sodium $5 \mathrm{mg} / \mathrm{kg}$, and rocuronium $0.8 \mathrm{mg} / \mathrm{kg}$. After tracheal intubation, lungs were ventilated with tidal volume $8 \mathrm{ml} / \mathrm{kg}$ and an inspiratory/expiratory ratio of 0.5 was adjusted. Respiratory rate was adjusted to maintain an $\mathrm{ETCO}_{2}$ between 30 and $40 \mathrm{mmHg}$. Maintenance was provided with a 50\% mixture of oxygen/nitrous oxide, sevoflurane of 1.0 minimum alveolar anesthetic concentration. Five minutes after induction of values were recorded at 5 minute intervals for 2 readings, i.e., at 5 and 10 minutes, followed by sitting to beach chair position (reverse Trendelenburg, $70^{\circ}$ ) and BIS values were recorded 5, 10, and 15 minutes after position change. Simultaneously, the following variables were recorded: heart rate $(\mathrm{HR})$, mean arterial pressure (MAP), $\mathrm{SpO}_{2}, \mathrm{ETCO}_{2}$, and end tidal sevoflurane (Etsevo). These measurements were all done before surgical incision.

All data are expressed as mean \pm standard deviation (SD). Statistical analysis was performed using SPSS version 21.0 (SPSS, Chicago, IL, USA). The correlation between BIS and MAP was analyzed with the Pearson correlation test and multivariative regression analysis was used to compare the effect of MAP on the BIS value. Repeated measures analysis of variance was conducted to test for changes in BIS, MAP, HR, $\mathrm{SpO}_{2}, \mathrm{ETCO}_{2}$, and Etsevo values in different positions. A $\mathrm{P}$ value $<0.05$ was considered statistically significant.

\section{Results}

Thirty patients (15 males, 15 females) were included in the study. Patients' characteristics are summarized in Table 1. There was a statistically significant decrease in BIS values in the beach chair position compared with supine position $(\mathrm{P}<0.01)$ (Fig. 1 and Table 2). The beach chair position also induced a significant decrease in MAP $(\mathrm{P}<0.01)$. Additionally, the correlations between MAP and BIS values were statistically significant (Pearson correlation coefficient: $0.696, \mathrm{P}<0.01$ ) and regression analysis revealed that increased MAP significantly raised BIS value $\left(R^{2}\right.$

Table 1. Patient Demographics $(\mathrm{n}=30)$

\begin{tabular}{lc}
\hline \multicolumn{1}{c}{ Variable } & Data \\
\hline Sex $(\mathrm{M} / \mathrm{F})$ & $15 / 15$ \\
Age $(\mathrm{yr})$ & $48 \pm 9.8$ \\
Body weight $(\mathrm{kg})$ & $67 \pm 8.9$ \\
Height $(\mathrm{cm})$ & $162 \pm 7.5$ \\
BIS, pre-general anesthesia & $94 \pm 3.7$ \\
\hline
\end{tabular}

Values are mean \pm SD. Pre-general anesthesia: before induction of anesthesia. 
$=0.48, \mathrm{P}<0.01)$ (Fig. 2). There were no significant changes in $\mathrm{HR}(\mathrm{P}=0.18), \mathrm{SpO}_{2}(\mathrm{P}=0.23), \mathrm{ETCO}_{2}(\mathrm{P}=0.11)$, or Etsevo ( $\mathrm{P}$ $=0.25)$ (Table 2$)$. There were no significant correlations between $\mathrm{BIS}$ values and $\mathrm{HR}, \mathrm{SpO}_{2}, \mathrm{ETCO}_{2}$, and Etsevo. All values are expressed as mean \pm standard deviation (SD).

\section{Discussion}

In our study, BIS values and MAP decreased along with sitting position change for arthroscopic shoulder surgery. Moreover, MAP was significantly correlated with BIS values in the sitting position for arthroscopic shoulder surgery.

The beach chair (sitting) position for arthroscopic shoulder surgery provides anatomical position, good surgical access, and reduced bleeding during surgery. Body responses to position change are caused by gravity. After a sitting position change, cerebral blood flow (CBF) goes down to the leg. Decrease of blood flow in the brain and heart reduces MAP. In one study [15], the authors suggested that cerebral blood flow is reduced

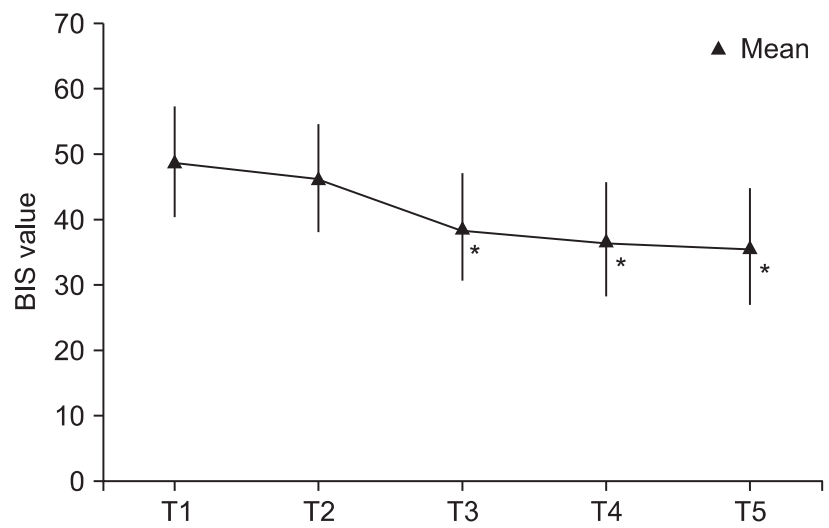

Fig. 1. Changes in bispectral index values in relation to changes in patient position. T1: 5 minutes after induction in supine position, T2: 10 minutes after induction in supine position, T3: 5 minutes after sitting position, T4: 10 minutes after sitting position, T5: 15 minutes after sitting position, BIS: bispectral index. The whiskers denote the range of the standard deviation around the mean values. ${ }^{*} \mathrm{P}<0.01$ compared to $\mathrm{T} 0$ or $\mathrm{T} 1$. using magnetic resonance imaging to measure the amount of $\mathrm{CBF}$, compared with the supine position. These distribution changes of cerebral blood might affect cerebral electrical activity and the dipole responsible for EEG waveform changes [16]. The findings support the suggestion that the beach chair position for arthroscopic shoulder surgery reduces cerebral electrical activity. Accordingly, EEG waveform changes and it affects BIS values. The present findings can be attributed to the hemodynamic changes associated with the sitting position.

Cerebral perfusion pressure (CPP) is the difference between MAP and intracranial pressure (ICP) [17]. Thus, reduced MAP corresponds to decreased CPP and cerebral hypoperfusion. Not uncommonly, neurologic complications during surgery in the beach chair position have been reported. Villevieille et al. [18] reported three cases in which cerebral ischemia occurred during arthroscopic shoulder surgery performed in the beach chair position under general anesthesia and interscalene plexus block. They suggested that brain ischemia is related to the decrease in CPP. A decrease in cerebral oxygen saturation $\left(\mathrm{rSO}_{2}\right)$ measured by near-infrared spectroscopy suggests a decrease in cerebral oxygen delivery and is associated with early postoperative neu-

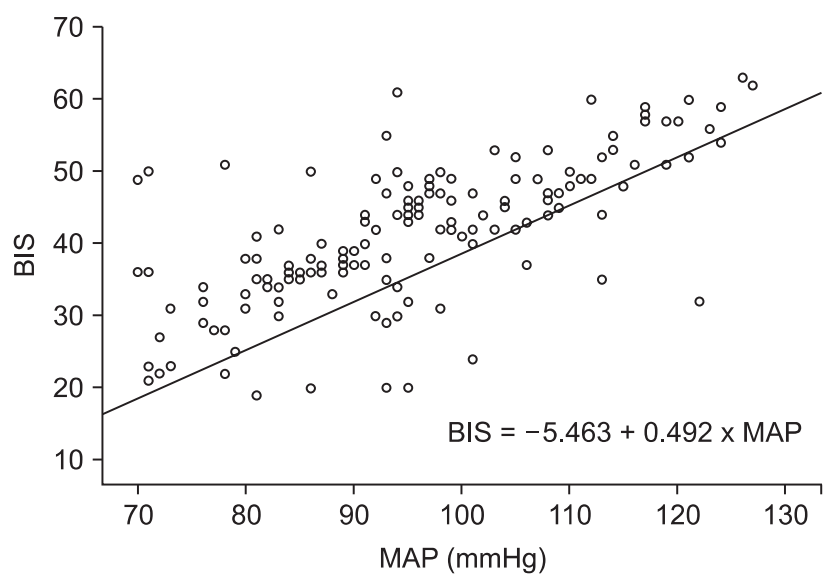

Fig. 2. The relationship between mean arterial pressure (MAP) and bispectral index (BIS). Pearson correlation coefficient is 0.696 . BIS = $-5.463+0.492 \times$ MAP, $\mathrm{R}^{2}=0.48, \mathrm{P}<0.01$.

Table 2. Changes in Bispectral Index Values And Patients' Hemodynamic Data: Heart Rate, Mean Arterial Pressure, End-tidal carbon Dioxide, and End-tidal Sevoflurane

\begin{tabular}{lccccc}
\hline \multicolumn{1}{c}{ Variables } & T1 & T2 & T3 & T4 & T5 \\
\hline HR (bpm) & $87.2 \pm 12.6$ & $88.0 \pm 11.3$ & $85.7 \pm 13.0$ & $85.2 \pm 9.7$ & $86.0 \pm 11.9$ \\
MAP (mmHg) & $109.7 \pm 9.5$ & $107.0 \pm 9.3$ & $89.8 \pm 8.6^{*}$ & $86.3 \pm 8.8^{*}$ & $84.3 \pm 8.1^{*}$ \\
ETCO $_{2}(\mathrm{mmHg})$ & $35.9 \pm 2.2$ & $36.1 \pm 2.5$ & $36.0 \pm 2.3$ & $36.0 \pm 2.2$ & $35.9 \pm 2.1$ \\
Etsevo (vol\%) & $1.7 \pm 0.1$ & $1.7 \pm 0.2$ & $1.7 \pm 0.1$ & $1.7 \pm 0.1$ & $1.7 \pm 0.1$ \\
BIS & $48.9 \pm 8.3$ & $46.5 \pm 8.2$ & $39.0 \pm 8.1^{*}$ & $37.0 \pm 8.6^{*}$ & $36.0 \pm 8.8^{*}$ \\
\hline
\end{tabular}

Values are mean \pm SD. T1: 5 minutes after induction in supine position, T2: 10 minutes after induction in supine position, T3: 5 minutes after sitting position, T4: 10 minutes after sitting position, T5: 15 minutes after sitting position, HR: heart rate, MAP: mean arterial pressure, EtCO ${ }_{2}$ : end-tidal carbon dioxide, Etsevo: end-tidal sevoflurane, BIS: bispectral index. ${ }^{*} \mathrm{P}<0.01$ compared to T1or T2. 
ropsychological dysfunction [19]. Hayashida et al. [20] reported that the BIS also makes allowances for the detection of cerebral hypoperfusion.

The study has some limitations. We could not monitor cerebral blood flow or cerebral perfusion. Intraoperative ICP monitoring and transcranial doppler were not used. Cerebral oximetry is a useful tool to monitor and predict the development of cerebral hypoperfusion and ischemia [21]. We could not simultaneously monitor CBF with BIS values and could not prove the correlation between $\mathrm{CBF}$ and BIS values. BIS and $\mathrm{rSO}_{2}$ by near infra-red spectroscopy combination can be a convenient cerebral ischemia monitor [22]. Further studies using a cerebral oximetry or transcranial doppler ultrasound with BIS monitoring are needed, if possible. Another unclear issue is whether the decreasing level of BIS associated with the beach chair position represents increasing anesthetic depth. Again, further study is required.

Kaki and Almarakbi [2] reported a position-related change in BIS readings. They observed significant increase in BIS values in the head-down position compared with the supine position, whereas the head-up position significantly decreased BIS compared with the supine position. Surgery was started regardless of a patient's position and the authors could not exclude the effect on BIS values by surgical stimuli and pain. To exclude the effect of surgical stimuli, we measured BIS values before surgery was started and studied only the effect of changing patient position on BIS values.

In conclusion, our study suggests that changes in sitting position for arthroscopic shoulder surgery decreases BIS values in concert with MAP compared with the supine position. While not definitive, we may assume that these effects are due to reduced cerebral blood flow.

\section{References}

1. Myles PS, Williams DL, Hendrata M, Anderson H, Weeks AM. Patient satisfaction after anaesthesia and surgery: results of a prospective survey of 10,811 patients. Br J Anaesth 2000; 84: 6-10.

2. Kaki AM, Almarakbi WA. Does patient position influence the reading of the bispectral index monitor? Anesth Analg 2009; 109: 1843-6.

3. Liu J, Singh H, White PF. Electroencephalographic bispectral index correlates with intraoperative recall and depth of propofol-induced sedation. Anesth Analg 1997; 84: 185-9.

4. Punjasawadwong Y, Boonjeungmonkol N, Phongchiewboon A. Bispectral index for improving anaesthetic delivery and postoperative recovery. Cochrane Database Syst Rev 2007; (4): CD003843.

5. Dahaba AA. Different conditions that could result in the bispectral index indicating an incorrect hypnotic state. Anesth Analg 2005; 101: 765-73.

6. Hirota K, Kubota T, Ishihara H, Matsuki A. The effects of nitrous oxide and ketamine on the bispectral index and $95 \%$ spectral edge frequency during propofol-fentanyl anaesthesia. Eur J Anaesthesiol 1999; 16: 779-83.

7. Detsch O, Schneider G, Kochs E, Hapfelmeier G, Werner C. Increasing isoflurane concentration may cause paradoxical increases in the EEG bispectral index in surgical patients. Br J Anaesth 2000; 84: 33-7.

8. Gallagher JD. Pacer-induced artifact in the bispectral index during cardiac surgery. Anesthesiology 1999; 90: 636.

9. Hemmerling TM, Migneault B. Falsely increased bispectral index during endoscopic shoulder surgery attributed to interferences with the endoscopic shaver device. Anesth Analg 2002; 95: 1678-9.

10. Wu CC, Lin CS, Mok MS. Bispectral index monitoring during hypoglycemic coma. J Clin Anesth 2002; 14: 305-6.

11. England MR. The changes in bispectral index during a hypovolemic cardiac arrest. Anesthesiology 1999; 91: 1947-9.

12. Doi M, Gajraj RJ, Mantzaridis H, Kenny GN. Effects of cardiopulmonary bypass and hypothermia on electroencephalographic variables. Anaesthesia 1997; 52: 1048-55.

13. Merat S, Levecque JP, Le Gulluche Y, Diraison Y, Brinquin L, Hoffmann JJ. BIS monitoring may allow the detection of severe cerebral ischemia. Can J Anaesth 2001; 48: 1066-9.

14. Bruhn J, Bouillon TW, Shafer SL. Electromyographic activity falsely elevates the bispectral index. Anesthesiology 2000; 92: 1485-7.

15. Alperin N, Lee SH, Mazda M, Hushek SG, Roitberg B, Goddwin J, et al. Evidence for the importance of extracranial venous flow in patients with idiopathic intracranial hypertension (IIH). Acta Neurochir Suppl 2005; 95: 129-32.

16. Schneider S, Brummer V, Carnahan H, Dubrowski A, Askew CD, Struder HK. What happens to the brain in weightlessness? A first approach by EEG tomography. Neuroimage 2008; 42: 1316-23.

17. Porter JM, Pidgeon C, Cunningham AJ. The sitting position in neurosurgery: a critical appraisal. Br J Anaesth 1999; 82: 117-28.

18. Villevieille T, Delaunay L, Gentili M, Benhamou D. Arthroscopic shoulder surgery and ischemic cerebral complications. Ann Fr Anesth Reanim 2012; 31: 914-8.

19. Yao FS, Tseng CC, Ho CY, Levin SK, Illner P. Cerebral oxygen desaturation is associated with early postoperative neuropsychological dysfunction in patients undergoing cardiac surgery. J Cardiothorac Vasc Anesth 2004; 18: 552-8. 
20. Hayashida M, Chinzei M, Komatsu K, Yamamoto H, Tamai H, Orii R, et al. Detection of cerebral hypoperfusion with bispectral index during paediatric cardiac surgery. Br J Anaesth 2003; 90: 694-8.

21. Ko SH, Cho YW, Park SH, Jeong JG, Shin SM, Kang G. Cerebral oxygenation monitoring of patients during arthroscopic shoulder surgery in the sitting position. Korean J Anesthesiol 2012; 63: 297-301.

22. Hayashida M, Kin N, Tomioka T, Orii R, Sekiyama H, Usui H, et al. Cerebral ischaemia during cardiac surgery in children detected by combined monitoring of BIS and near-infrared spectroscopy. Br J Anaesth 2004; 92: 662-9. 